\title{
Multiresponse modelling of the caramelisation reaction
}

\author{
Mafalda Quintas, Carla Guimarães, João Baylina, Teresa R.S. Brandão, Cristina L.M. Silva* \\ Escola Superior de Biotecnologia, Universidade Católica Portuguesa, R. Dr. António Bernardino de Almeida, 4200-072 Porto, Portugal
}

Keywords: Multiresponse modelling; Sucrose thermal degradation; Caramelisation reaction; Kinetic parameters

\begin{abstract}
Multiresponse modelling is a powerful tool for studying complex kinetics of reactions occurring in food products. This modelling technique uses information of reactants and products involved, allowing insightful kinetic parameters estimation and helping in clarifying reaction mechanisms. One example of a complex reaction that occurs in food processing is the caramelisation reaction. Caramelisation is the common name for a group of reactions observed when carbohydrates are exposed to high temperatures.

The objective of this work was to apply multiresponse regression in developing a mathematical mechanistic model that describes sucrose thermal degradation and caramelisation products formation in highly concentrated sucrose solutions, with different water contents and under various temperatures.

Results demonstrated the usefulness of multiresponse modelling in understanding reaction mechanisms in food matrices. A mechanistic model for the caramelisation reaction was proposed, which successfully described the experimental data of concentrated solutions in the 30.03 to $12.20 \%$ $(w / w)$ water content range. Furthermore, good predictions of temperature and water content effects were achieved. For extremely low water content systems $(3.58 \%(w / w))$, the proposed mechanistic model failed to describe experimental data, indicating different reaction pathways.
\end{abstract}

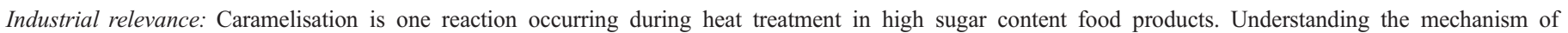

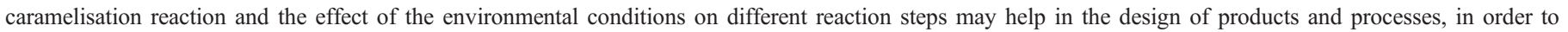

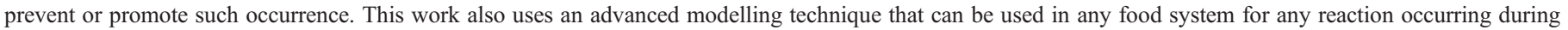
processing.

\section{Introduction}

Food reactions often do not occur isolated but rather within a chain of complex reactions, all dependent on several different environmental conditions. Thus, food scientists frequently use pure mathematical or semi-empirical approaches, by modelling quality parameters' changes (such as nutrient content, colour or flavour) with time using zero or first order kinetics. These approaches have been successfully applied to several quality factors of thousands of different products under various environmental conditions. Still, after all this scientific effort, food science is not able to fully understand the reaction mechanisms and even less the influence of environmental factors on each step of the mechanism. Measuring several responses of a food system at the same time and using all the information available when modelling experimental data, can be a powerful tool for solving and clarifying these issues. This can be done using multiresponse modelling (Box \& Draper, 1965; Stewart, Caracotsios, \& Sorensen, 1992). This modelling approach accounts for kinetic information of both reactants and products involved in the reaction, resulting in insightful parameter estimation and, consequently, in more accurate model predictions.

In food science, multiresponse modelling has been successfully applied to enzymatic reactions (Malcata, Hill Jr., \& Amundson, 1991; Torres, Lessard, \& Hill, 2003; Barros \& Malcata, 2004) and other studies, like chlorophyll degradation in foods (van Boekel, 1999) and lactic fermentation during

\footnotetext{
* Corresponding author. Tel.: +35122558 00 58; fax: +351 225090351.

E-mail address: clsilva@esb.ucp.pt (C.L.M. Silva).
} 


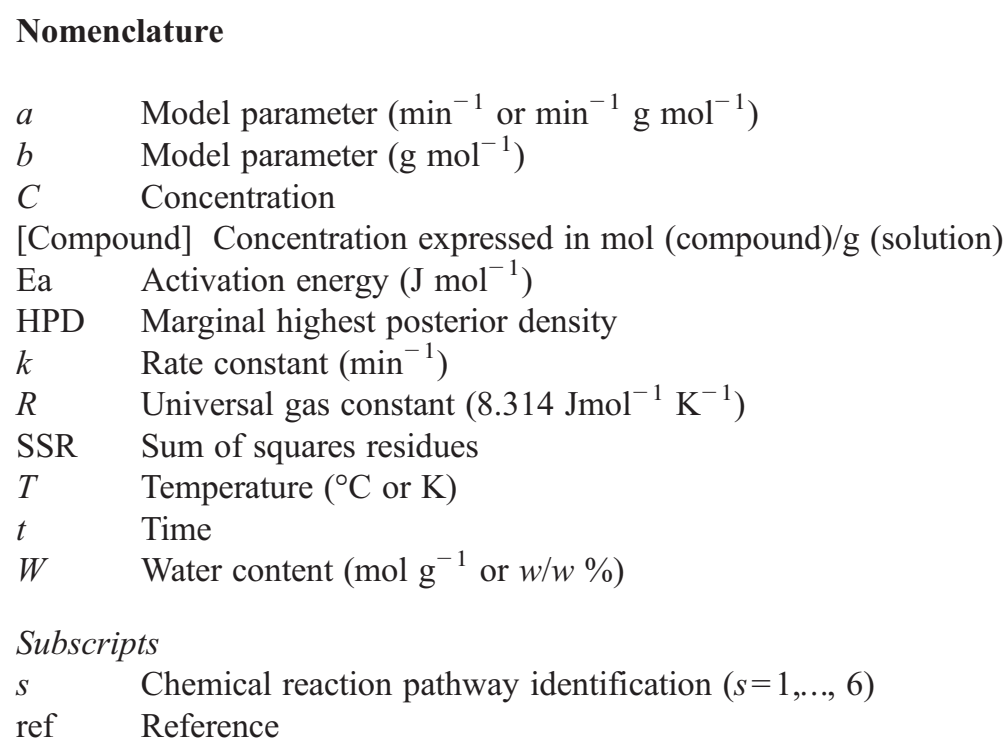

pickled carrot manufacture (Nabais \& Malcata, 1997). This approach has also been widely used in understanding the Maillard reaction (van Boekel, 1998) and, recently, was used to elucidate the acrylamide formation in cooked foods (Knol et al., 2005).

Caramelisation is the common name for a group of reactions that occur when carbohydrates are exposed to high temperatures. These reactions differ from Maillard reactions, since no amino groups are involved. They often occur during the preparation of traditional sucrose syrups and caramels, which are extensively used in confectionery and pastry products.

Sucrose caramelisation reaction, i.e. sucrose degradation and products formation, has been studied by several authors. In the past decades, great insight was gained on the reactions mechanism (Mauch, 1971; Richards, 1986; Clarke, Edye, \& Eggleston, 1997). However, kinetic studies on this subject are mainly related with sucrose degradation (Vukov, 1965; Schoebel, Tannenbaum, \& Labuza, 1969; Buera, Chirifie, Resnik, \& Wetzler, 1987; Eggleston, Trask-Morrel, \& Vercellotti, 1996) or with the formation of caramelisation products (Lee \& Nagy, 1988; Arena, Fallico, \& Maccarone, 2001).

The caramelisation reaction occurs at high temperatures in the presence or absence of catalysts (acids, basis, salts or impurities). This reaction can be observed in dilute or concentrated solutions (amorphous state), and in the crystal form. Due to the large number of reaction pathways and even larger number of products formed during the caramelisation reaction, kinetic studies based on the caramelisation reaction mechanism are complex. The complexity of the reaction makes the use of multiresponse modelling very attractive, since it also allows clarifying the main reaction pathways that directly depend on the process conditions.

This work aimed at developing a mechanistic multiresponse model able to describe sucrose caramelisation in concentrated solutions without catalyst, thus demonstrating multiresponse modelling usefulness in such studies.

\section{Theoretical considerations}

\section{Sucrose degradation into caramel}

As already stated, sucrose thermal degradation in the absence of amino groups (caramelisation) occurs under a complex group of reactions, with many different pathways. Each possible pathway may be preponderant under given environmental conditions. In this work we focus on the case where sucrose in very concentrated solutions (above room temperature saturation), at neutral $\mathrm{pH}$ and in the absence of impurities, is heated at high temperatures. Under these conditions, the effect of heat is similar to the effect of using lower temperatures in acidic conditions, and the reaction mechanisms can be considered to be identical (Mauch, 1971).

The first reaction step in the caramelisation reaction is sucrose hydrolysis (please see Fig. 1a). This takes place by protonation of the glycosidic linkage (Mauch, 1971; Richards, 1986; Eggleston et al., 1996; Clarke et al., 1997). The $\mathrm{H}^{+}$used in this reaction step can be derived from water (or even sucrose) dissociation at high temperatures and also from acidic reaction products (Richards, 1986; Lowary \& Richards, 1988; Eggleston et al., 1996).

Under neutral conditions, sucrose hydrolysis yields D-glucose and a fructose oxocarbonium ion (Richards, 1986; Lowary \& Richards, 1988; Eggleston et al., 1996; Clarke et al., 1997). This fructose carbocation can react with: i) a water molecule to form fructose and regenerate the catalyst $\mathrm{H}^{+}$, or ii) another carbohydrate molecule present in solution (sucrose, glucose, fructose or even another fructose carbocation) to form oligosaccharides. Moreover, this fructose carbocation may also undergo non-specific reactions to form a wide range of products, including: anhydrosaccharides, 5-hydroxymethyl-furfural (HMF) and organic acids (Richards, 1986; Eggleston et al., 1996; Clarke et al., 1997).

The oligosaccharide and anhydro-sacharide components of caramel have been extensively studied (Defaye \& GarcíaFernández, 1995; Manley-Harris \& Richards, 1997). However, 


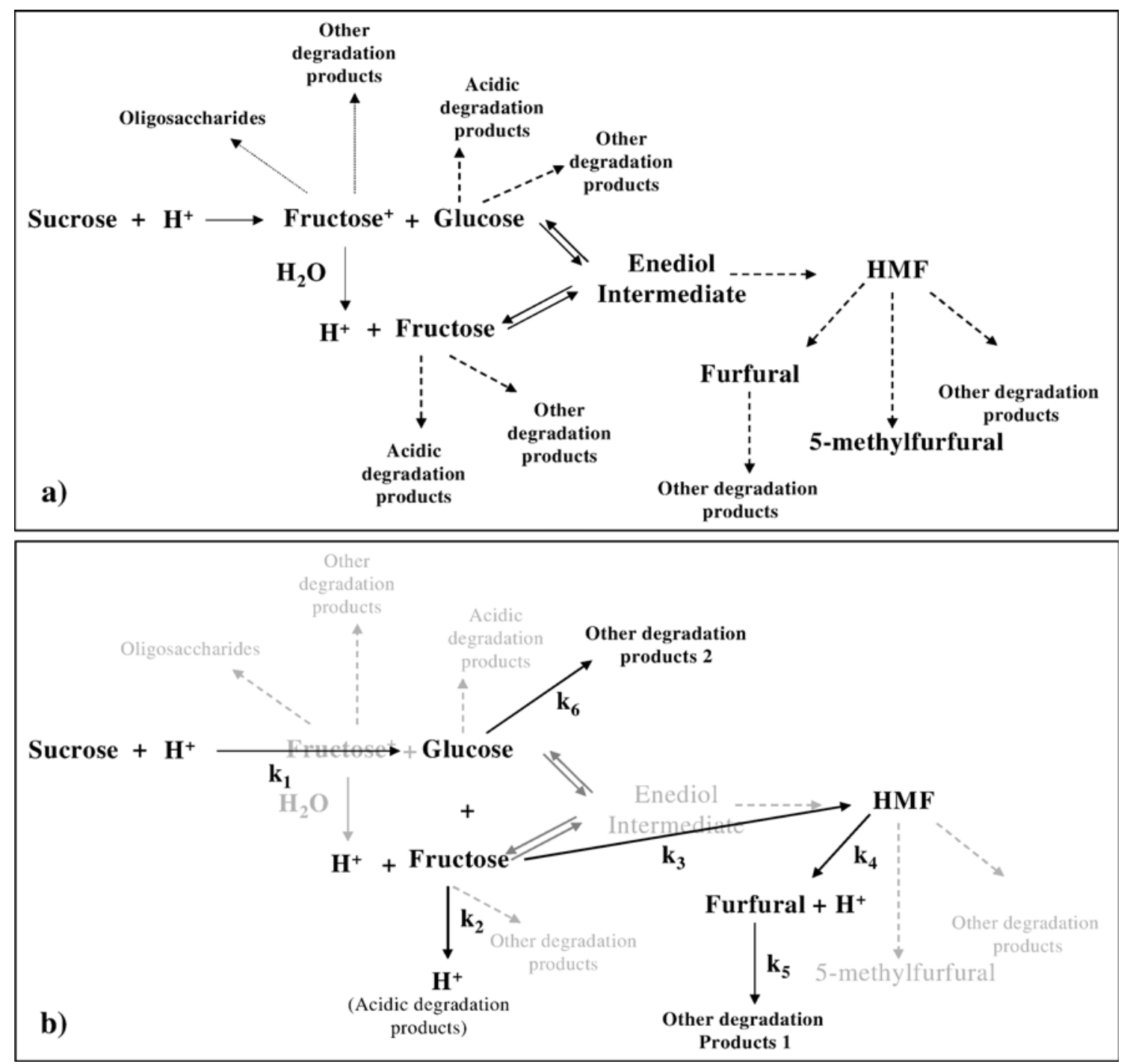

Fig. 1. Schematic representation of sucrose caramelisation mechanism (a) based on literature search, and (b) proposed reaction pathways based on experimental data and multiresponse modelling procedures.

the extent of production of these substances is dependent on reaction conditions and is typically favoured by extreme acidic/ high temperatures reaction conditions (Antal Jr., Mok, \& Richards, 1990; Manley-Harris \& Richards, 1997), which is not the present case.

Further degradation of fructose and glucose is responsible for the formation of other compounds, with special preponderance of HMF (Mauch, 1971; Lowary \& Richards, 1988; Antal Jr. et al., 1990; Kroh, 1994; Eggleston et al., 1996; Clarke et al., 1997). The mechanism of such reaction is generally accepted to be an open chain $\beta$-elimination mechanism, which proceeds via an enediol intermediate to 3-deoxyhexulose (Kroh, 1994; Clarke et al., 1997). With the further development of the caramelisation reaction, HMF can be degraded to other products, including furfural, via fragmentation reaction (with indirect subsequent $\mathrm{H}^{+}$release) and 5-methylfurfural, via reduction reaction (Mauch, 1971; Antal Jr. et al., 1990; Kroh, 1994; Clarke et al., 1997).

The global sucrose caramelisation reaction at high temperatures and neutral $\mathrm{pH}$ can then be generally described by the scheme in Fig. 1a. However, one must always bear in mind that this is a simplification of the reaction steps and some intermediate products and reactions are not considered (dashed arrows in Fig. 1a).

\section{Materials and methods}

\section{Experimentalprocedures}

In order to characterise the caramelisation reaction, sucrose and its degradation products were quantified along the reaction at different temperatures and initial water contents. pHmeter readings were also monitored, in order to confirm the $\mathrm{pH}$ drop during the initial reaction steps.

\section{Sample preparation}

Sucrose solutions of 70 to $87.5 \%$ ( $\left.w_{\text {sucrose }} / w_{\text {solution }}\right)$ were prepared by weighing commercial sucrose and adding distilled water in the desired proportion. The mixtures were then heated in a microwave oven (medium power) for short periods (1 min), 
intercalated with agitation until complete sucrose dissolution (Braga da Cruz, MacInnes, Oliveira, \& Malcata, 2002).

Sucrose solutions of $97 \%\left(w_{\text {sucrose }} / w_{\text {solution }}\right)$ were also prepared. Freeze-dried sucrose (commercial) was equilibrated with a saturated salt solution of lithium bromide (purum p.a., Fluka), of aw $@ 27{ }^{\circ} \mathrm{C} 6 \%$, under vacuum, until constant weight.

A Karl Fisher coulometric determination (684 K coulometer, Metrohm, Switzerland) was used to measure the real moisture content of concentrated sucrose solutions. At least three different batches were prepared for each concentration and each batch was analysed three times. The 95\% Standard Error (SE) of the samples water content were calculated. Results showed the prepared solutions were $30.03 \pm 0.28,25.30 \pm 0.63$, $16.32 \pm 0.82,12.20 \pm 0.42$ and $3.58 \pm 0.50\left(w_{\text {water }} / w_{\text {solution }} \%\right)$ in water content.

The concentrated sucrose solutions were poured into Thermal Death Time (TDT) cans, $6 \mathrm{~cm}$ diameter and $0.8 \mathrm{~cm}$ height $(208 \times 0.06$, American National Can, USA), sealed under vacuum, and processed isothermally at 100, 120, 140, $160 \mathrm{e}$ $180 \pm 2{ }^{\circ} \mathrm{C}$ in an oil bath (polyethelene glycol 400, Clariant) for different times.

Two true replicates of each reaction condition (processing temperature and water content) were carried out.

The total acidity of the prepared samples was determined by acid-base titration, in order to confirm that solutions were indeed neutral $(\mathrm{pH}=7)$.

\section{Analytical determinations}

Sucrose, fructose and glucose : Sucrose, fructose and glucose contents of the concentrated sugar solutions were determined using High Pressure Liquid Chromatography (HPLC). Standard solutions were prepared from sucrose (for biochemistry, Merck), D-fructose (for biochemistry, Merck) and D-glucose (monohydrat for biochemistry, Merck). Both samples and standard solutions were filtered $(0.45 \mu \mathrm{m})$ and analysed in duplicate in a HPLC system (Jasco, Japan), equipped with a PU-1580 pump and an AS-1555 injector. The column was a Merck Licrospher ${ }^{\circledR} 100 \mathrm{NH} 2(5 \mu \mathrm{m})$. The mobile phase, acetonitrile (Isocratic Grade, Lichrosolv, Merck)/water (80:20), was running at $1.5 \mathrm{ml} / \mathrm{min}$. The peaks were detected using a Refractive Index detector (RI-1530, Jasco) and analysed using Jasco-Borwin software v.1.50 (JMBS Developments, Fontaine, France). Typical retention times were 4.20, 4.60 and 6.28 min for fructose, glucose and sucrose, respectively. Results were expressed in mol (sugar)/g (solution).

\section{5-hydroxymethylfurfural, furfural and 5-methylfurfural}

HMF, furfural and 5-methylfurfural contents of the sugar syrups were determined using HPLC. Standard solutions were prepared from HMF (pure, Fluka), furfural (puriss., Fluka) and 5-methylfurfural (practical, Fluka). Both samples and standard solutions were filtered and analysed in duplicate in the HPLC system, as described above. The column was a Waters Spherisorb ${ }^{\circledR} \mathrm{S} 5$ ODS2 $\mathrm{C}_{18}$. The mobile phase, acetonitrile (Isocratic Grade, Lichrosolv, Merck)/water (70:30), was run- ning at $1.2 \mathrm{ml} / \mathrm{min}$. The peaks were detected using a UV detector (UV-1575, Jasco) set at $284 \mathrm{~nm}$ and analysed using Jasco-Borwin software v.1.50 (JMBS Developments, Fontaine, France). Typical retention times were 2.63, 3.54 and 4.42 min for HMF, furfural and 5-methylfurfural, respectively. Results were expressed in $\mathrm{mol}$ (compound)/g (solution).

\section{Monitoring acidity changes during the reaction}

After heat processing, samples acidity was assessed using a pHmeter (Crison GLP 22, Barcelona, Spain) at room temperature. For the $3.58 \%(w / w)$ water content samples, a previous dilution, equivalent in all cases, was made. This was due to the fact that these were not viscous solutions, but amorphous glassy systems, disabling direct measurements.

The use of $\mathrm{pH}$ electrodes in acidity measurements of viscous solutions must be undertaken with extreme caution, since deviations on the measurement of the proton activity may occur (Clarke et al., 1997). Consequently, experimental observations may not correspond to real $\mathrm{pH}$ values. Nevertheless, the objective in this measurement was to assess changes of the solutions' acidity during the reaction course and the error inherent to all measurements was of the same magnitude. Thus, for comparative purposes the method was acceptable. However, pHmeter readings in such conditions can not be directly translated to $\left[\mathrm{H}^{+}\right]$and such result can not be used as a response in the modelling procedure.

\section{Modelling procedures}

The development of the most appropriate model for describing the caramelisation mechanism was based on proposing possible reaction pathways (Fig. 1a). For each assumed mechanism, the rate of reaction of all components involved was defined. The obtained system of differential equations composed the model of the caramelisation reaction.

The models were fitted to experimental data points by multiresponse regression schemes, provided by Athena Visual Studio software (www.athenavisual.com), which allows estimating the reaction rate constants using the determinant criterion of the Bayesian approach (Box \& Draper, 1965; Bates \& Watts, 1988; Seber \& Wild, 1989; Stewart et al., 1992; van Boekel, 1996). Mathematically, the model that best described the experimental data was selected based on fulfilment of regression analysis: i.e., minimization of the sum of squares of the residuals (SSR) and independent random residuals, normally distributed with zero mean and constant variance (Bates \& Watts, 1988).

After selecting the best model, the temperature dependence of rate constants was described by an Arrhenius equation and a one-step multiresponse regression analysis was carried out. Water content effects were also included in the Arrhenius parameters (i.e. pre-exponential factors and activation energies), by performing a global fit of all experimental data.

Quality of the regressions was assessed by SSR and visual inspection of residuals' randomness. Parameters' precision was evaluated by the $95 \%$ highest posterior density (HPD) intervals (Box \& Draper, 1965; Bates \& Watts, 1988; Seber \& Wild, 1989; Stewart et al., 1992; van Boekel, 1996). 


\section{Results and discussion}

\section{Experimental results}

Analysis of heat treated samples along processing revealed a lag phase on sucrose degradation and product formation (Fig. 2). This lag phase in sucrose degradation, in highly concentrated and neutral solutions treated at high temperatures, has been previously reported and mathematically described in literature (Richards, 1986; Lowary \& Richards, 1988; Eggleston et al., 1996; Clarke et al., 1997; Quintas, Brandão \& Silva, 2007).

Literature suggests that the existence of a lag phase, and observed autocatalytic nature, is due to the formation of weak acids along caramelisation, which accelerates the reaction (Mauch, 1971; Richards, 1986; Lowary \& Richards, 1988; Eggleston et al., 1996). This was confirmed by the observed drop on pHmeter readings (Fig. 2).

Experimental results showed that after an initial phase of delay, sucrose content rapidly decreases and glucose and fructose start to form (Fig. 2). Short time after, HMF is detected, followed by furfural. Later in the reaction, 5-methylfurfural can also be identified. However, the later compound could not be quantified in all of the experiments. This is due to reactions time, which in those cases was not sufficient to allow 5-methylfurfural formation. This observation led to the decision of not including this compound in modelling procedures.

\section{Modelling sucrose degradation in to caramel}

The mathematical description of the sucrose caramelisation reaction was based on mechanisms referred in literature. As already stressed, the scheme presented in Fig. 1a) is a general representation of the possible reaction pathways. Among all pathways presented, some were selected as preferred to occur. Such selections, and subsequent mechanisms proposed, were based on: i) experimental measurements of the reactants and products and ii) mathematically, by the degrees of freedom of the system of differential equations and number of parameters to estimate. A considerable number of mechanisms were tested (results not shown). The pathway proposed in Fig. 1b) fulfilled multiresponse regression analysis of the experimental data. The corresponding differential equations, that express the rate of reactions taken into consideration, are enumerated in Eqs. (1)-(8).

$\frac{\mathrm{d}[\text { Sucrose }]}{\mathrm{d} t}=-k_{1}[$ Sucrose $]\left[\mathrm{H}^{+}\right]$

$\frac{\mathrm{d}\left[\mathrm{H}^{+}\right]}{\mathrm{d} t}=k_{2}[$ Fructose $]+k_{4}[\mathrm{HMF}]$

$\frac{\mathrm{d}[\text { Fructose }]}{\mathrm{d} t}=k_{1}[$ Sucrose $]\left[\mathrm{H}^{+}\right]-k_{3}[$ Fructose $]-k_{2}[$ Fructose $]$

$\frac{\mathrm{d}[\text { Glucose }]}{\mathrm{d} t}=k_{1}[$ Sucrose $]\left[\mathrm{H}^{+}\right]-k_{6}[$ Glucose $]$

$\frac{\mathrm{d}[\mathrm{HMF}]}{\mathrm{d} t}=k_{3}[$ Fructose $]-k_{4}[\mathrm{HMF}]$ $\frac{\mathrm{d}[\text { Furfural }]}{\mathrm{d} t}=k_{4}[\mathrm{HMF}]-k_{5}[$ Furfural $]$

$\frac{\mathrm{d}[\text { Other Products }]}{\mathrm{d} t}=k_{5}[$ Furfural $]$

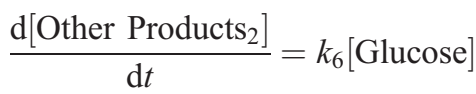

The mechanism proposed (Fig. 1b) only accounts for the main reaction pathways: i.e., the fact that this model does not consider the step of glucose degrading into HMF, does not mean that this step is not occurring, it only indicates that, kinetically and under the experimental conditions imposed, production of HMF from fructose is favoured. This preferential pathway has been described by several authors when discussing the higher reactivity of fructose over glucose (Mauch, 1971; Richards, 1986; Lee \& Nagy, 1988; Lowary \& Richards, 1988; AntalJr. et al., 1990; Arena et al., 2001). However, other pathways may emerge, if different processing conditions are used.

The model formed by the system of Eqs. (1)-(8) was fitted to experimental data. Constant rates $\left(k_{1}\right.$ to $\left.k_{6}\right)$ were estimated for fixed values of processing temperature and sucrose solutions water content. The proposed model successfully described the experimental data, as can be observed in the example presented in Fig. 2. Nevertheless, it is convenient to bear in mind that the mathematical model can only be "tentatively entertained" (Box \& Hunter, 1965). As an example, in the present study, acidity changes were monitored using a pHmeter, which is not able to give an exact $\mathrm{H}^{+}$concentration (please see Materials and methods section). Measurements of the organic acids during this reaction may have revealed a different mathematical model, since accurate $\mathrm{H}^{+}$concentration determination would allow using $\left[\mathrm{H}^{+}\right]$has a response in the regression procedure.

Drawbacks in modelling procedures occurred for sucrose solutions with $3.58 \%(w / w)$ water content. This may be explained by the fact that these are amorphous glassy systems at room temperature, with extremely low water content — in sucrose hydrolysis, water can also act as a solvent or reactant (Labuza, Tannenbaum, \& Karel, 1970). Under these conditions a different reaction mechanism may have occurred. In face of such observations, experimental results obtained for this concentration level were excluded from further modelling procedures.

\section{Temperature and water contente ffects}

Temperature is known to have a significant effect on food reaction kinetics. This effect is often translated into a dependence of the kinetic parameters on temperature, which has been widely studied and can be generally expressed with an Arrhenius type equation, using a finite reference temperature (Haralampu, Saguy, \& Karel, 1985; Peleg, 1992; Cohen, Birk, Mannheim, \& Saguy, 1994; van Boekel, 1996):

$k=k_{\text {ref }} \exp \left(-\frac{\mathrm{Ea}}{R}\left(\frac{1}{T}-\frac{1}{T_{\text {ref }}}\right)\right)$ 


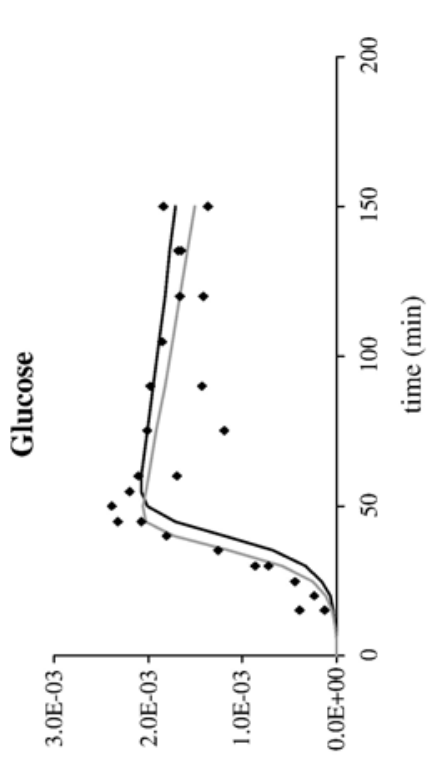

(ฐ/[ow) 0

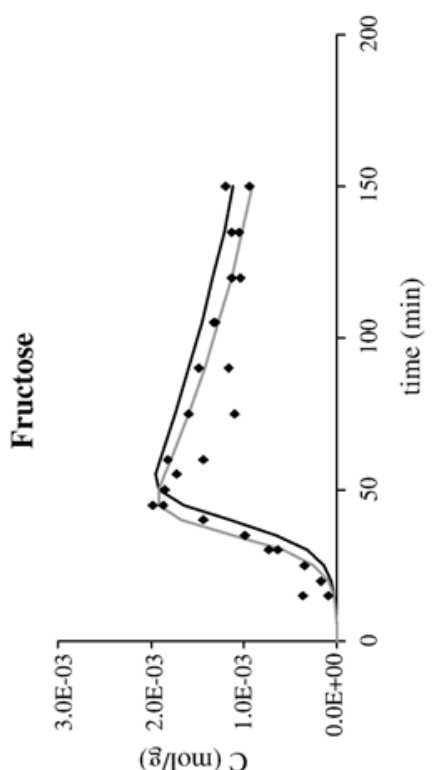

(รื/ןou) ว

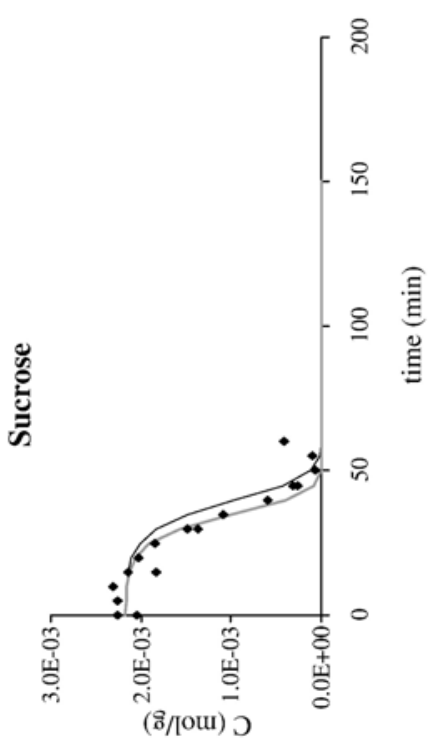

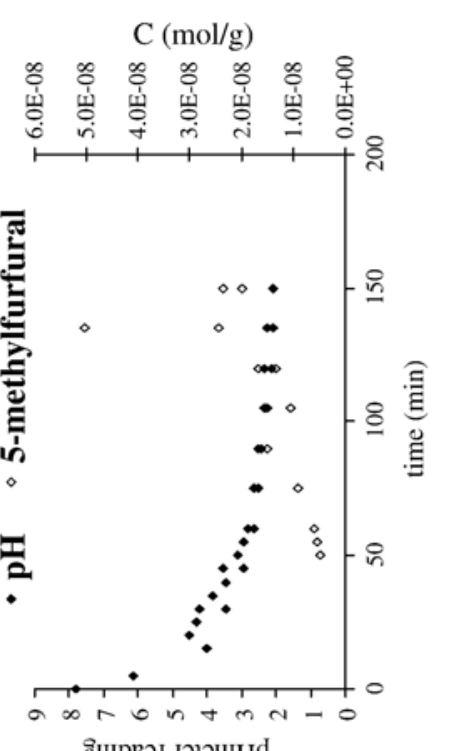

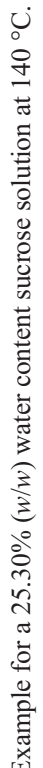

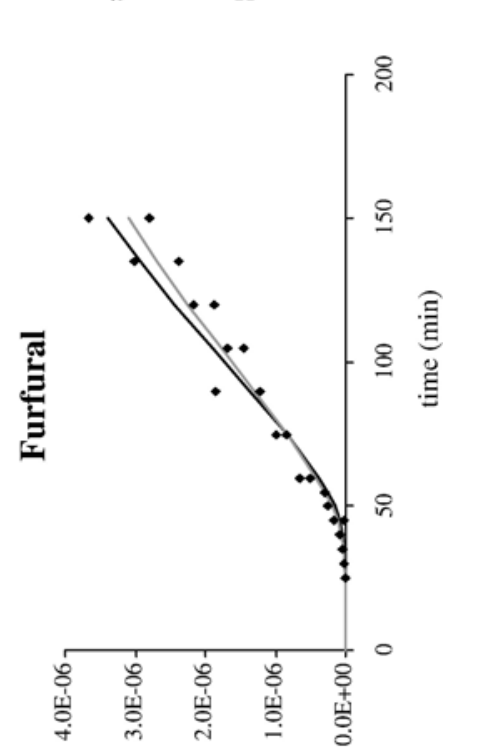

(ฮื/[ou) ว

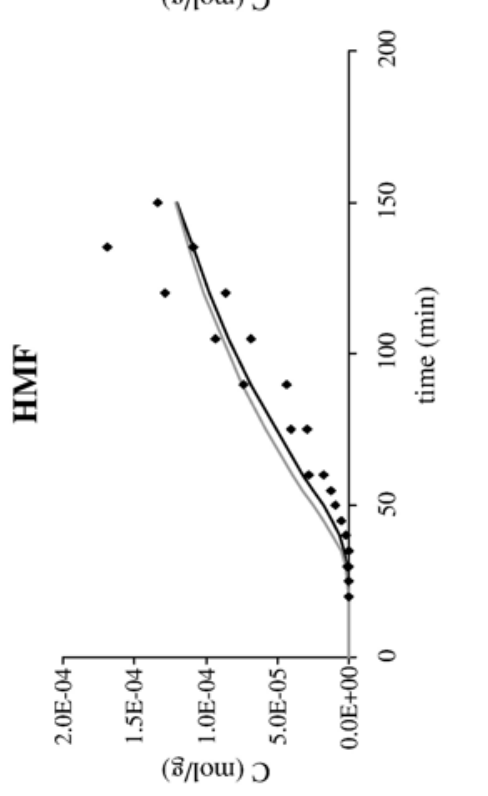



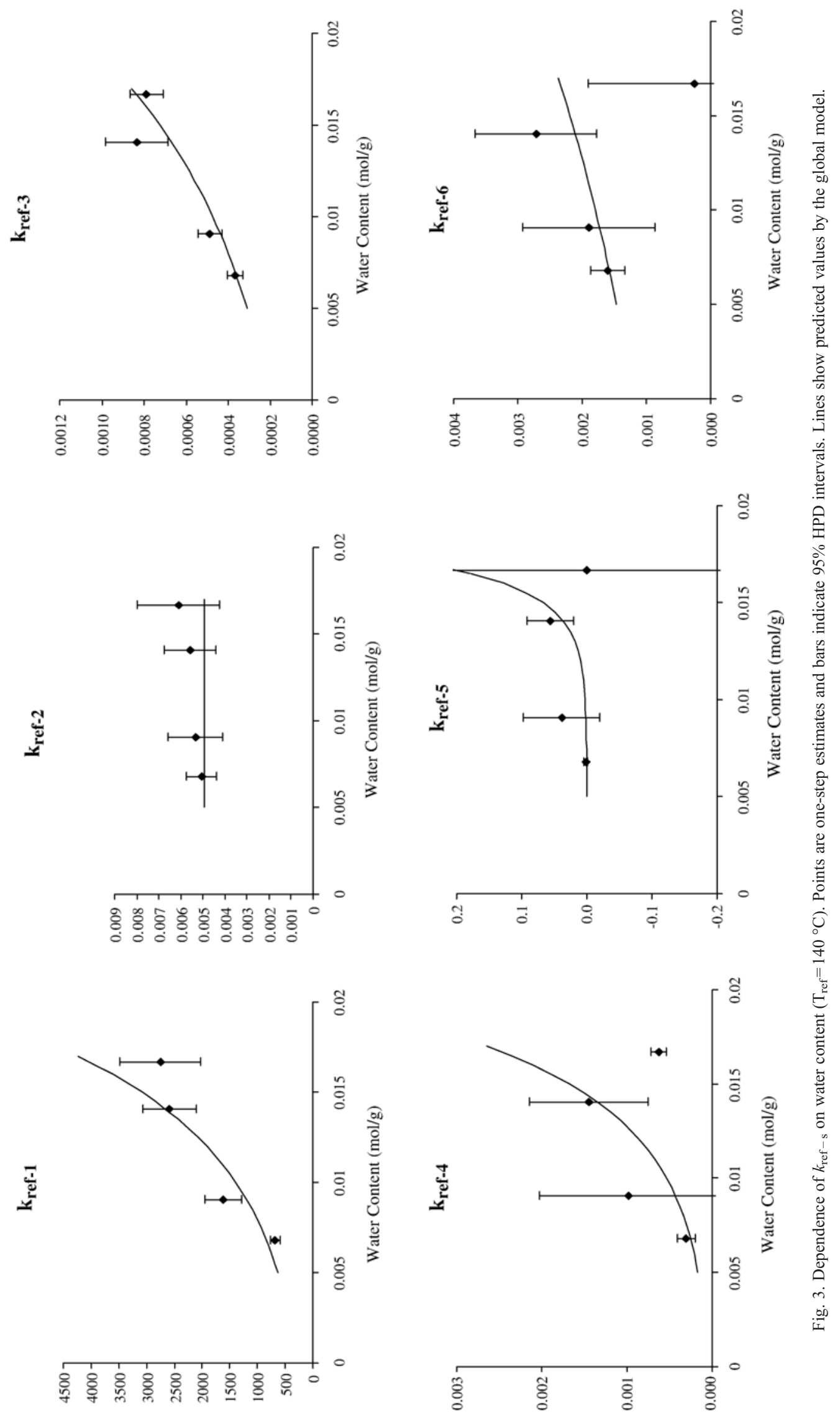
a)

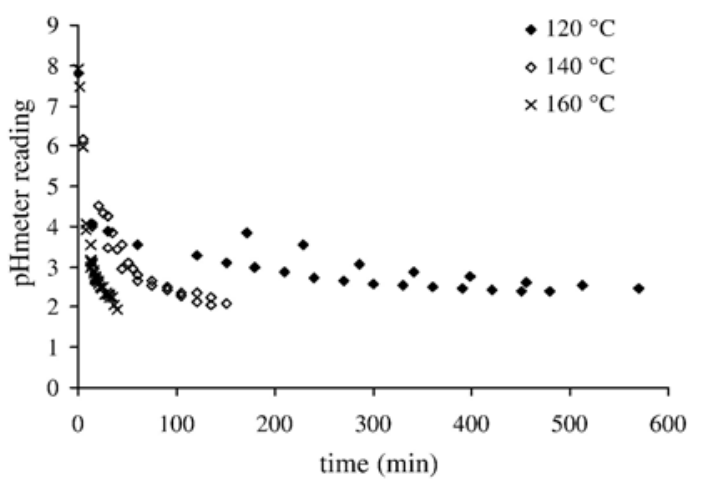

b)

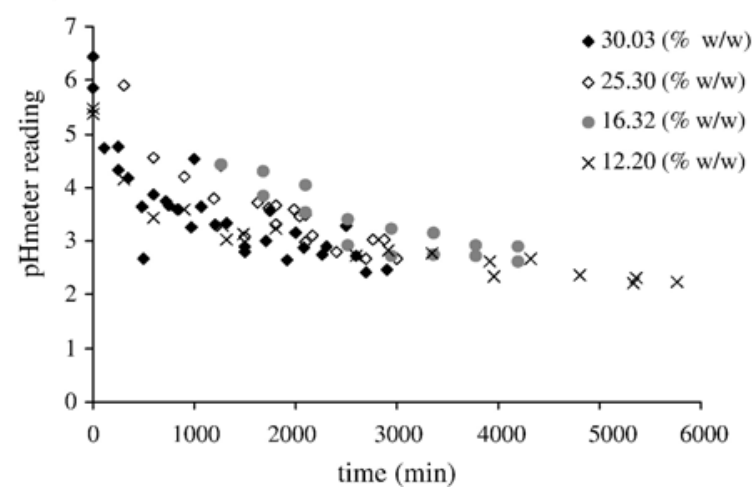

Fig. 4. Effect of (a) temperature and (b) water content on pHmeter reading of sucrose solutions during heat treatment. Results are for (a) $25.30 \%(w / w)$ water content solutions processed at different temperatures and for (b) different water content solutions processed at $100{ }^{\circ} \mathrm{C}$.

where $\mathrm{k}$ is the rate constant, Ea the activation energy, $k_{\text {ref }}$ the rate constant at finite reference temperature, $T_{\text {ref }}$, and $R$ the universal gas constant. It has been proven that correlation between parameters and the confidence intervals is minimised if $T_{\text {ref }}$ corresponds to the middle temperature $\left(140{ }^{\circ} \mathrm{C}\right.$ in the present case) of the experimental range (Cohen et al., 1994; van Boekel, 1996).

In systems with reduced molecular mobility, water content may also affect reactions kinetics, due to water's plasticization effect (Slade \& Levine, 1991; Karel, 1993; Bell \& Labuza, 1994; Kouassi \& Roos, 2001). The water content effect on reaction kinetics can be included in the Arrhenius model parameters, on the basis of experimental data and fitting procedures (Saguy \& Karel, 1980).

Kinetic parameters, $k_{\text {ref }-s}$ and $E_{a-s}$, of each reaction step $(s=1, \ldots 6$ is the pathway identification) were estimated for fixed water content levels, with the purpose of studying the influence of this factor on the estimates.

Results indicated that water content has no significant effect on activation energies of all reaction steps (results not shown). This observation has been previously reported and discussed (Saraiva, Oliveira, Hendrickx, Oliveira, \& Tobback, 1996; Quintas et al., 2007)) when narrow ranges of water content are considered - in the present study, water content ranges from 12.20 to $30.03 \%(w / w)$.
In relation to $k_{\mathrm{ref}-s}$, water content affected significantly all parameters, excepting $k_{\text {ref }-2}$ (i.e. fructose degradation into acidic degradation products) (Fig. 3). This can be an indication that the mechanism of fructose degradation into acidic products is significantly affected by temperature, but not by the amount of water molecules present in solution. This hypothesis is supported by the observed effects of temperature and water content on pHmeter readings drop during the reaction (Fig. 4).

The relationships between $k_{\mathrm{ref}-s}(s=1$ and 3$)$ and water content were exponential (Fig. 3). Regarding $k_{\text {ref }-s}(s=4,5$ and $6)$, the relationship with water content was less evident, probably due to mathematical drawbacks in parameter estimation, justified by the assumption of reaction pathways of components that were not experimentally measured (i.e., $\left[\mathrm{H}^{+}\right]$, for $k_{\text {ref }-4}$, other degradation products 1 , for $k_{\text {ref }-5}$ and other degradation products 2 , for $k_{\text {ref }-6}$ ). However, such relationships could be approximately described by exponential relationships (Fig. 3).

Based on these results, a global model, including both temperature and water content effects, was considered. This global model was formed by the system of differential Eqs. (1)-(8) combined with the Arrhenius relation, where $k_{\text {ref }-2}=$ constant, the remaining $k_{\text {ref }-s}=a_{s} \exp \left(b_{s} W\right)(s=1,3,4,5$ and 6) and all activation energies are constant ( $W$ is water content and $a_{s}$ and $b_{s}$ are coefficients to be estimated). Results of multiresponse regression analysis are included in Table 1 . The sum of squares of the residuals was $2.094 \times 10^{-4}$. The model was also evaluated in terms of adequacy for describing experimental data and in parameters' precision. The later can be clearly evaluated by the $\%$ of variation listed in Table 1, which was calculated dividing the halved $95 \%$ HPD interval by the estimate. Excepting $a_{5}$ and $b_{6}$, all other parameters were estimated with satisfactory

Table 1

Estimated parameters of the global model, which includes temperature and water content effects on the rates of the caramelisation reaction

\begin{tabular}{|c|c|c|}
\hline \multirow[t]{4}{*}{ Parameter } & \multicolumn{2}{|l|}{ Global model } \\
\hline & \multicolumn{2}{|l|}{$k_{\text {ref }-2}=$ const. } \\
\hline & \multicolumn{2}{|l|}{$k_{\text {ref }-s}=a_{s} \exp \left(b_{s} W\right)_{s=1,3,4,5}$ and 6} \\
\hline & (Estimate $\pm 95 \%$ HPD) interval & $\%$ of variation \\
\hline$\overline{k_{\text {ref }-2}\left(\min ^{-1}\right)}$ & $4.94 \times 10^{-3} \pm 4.69 \times 10^{-4}$ & 10 \\
\hline$E_{a-1}\left(\mathrm{~J} \mathrm{~mol}^{-1}\right)$ & $9.68 \times 10^{4} \pm 4.15 \times 10^{3}$ & 4 \\
\hline$E_{a-2}\left(\mathrm{~J} \mathrm{~mol}^{-1}\right)$ & $1.01 \times 10^{5} \pm 4.48 \times 10^{3}$ & 4 \\
\hline$E_{a-3}\left(\mathrm{~J} \mathrm{~mol}^{-1}\right)$ & $1.28 \times 10^{5} \pm 2.95 \times 10^{3}$ & 2 \\
\hline$E_{a-4}\left(\mathrm{~J} \mathrm{~mol}^{-1}\right)$ & $1.39 \times 10^{5} \pm 4.37 \times 10^{3}$ & 3 \\
\hline$E_{a-5}\left(\mathrm{~J} \mathrm{~mol}^{-1}\right)$ & $1.33 \times 10^{5} \pm 2.41 \times 10^{4}$ & 18 \\
\hline$E_{a-6}\left(\mathrm{~J} \mathrm{~mol}^{-1}\right)$ & $1.25 \times 10^{5} \pm 7.47 \times 10^{3}$ & 6 \\
\hline$a_{1}\left(\min ^{-1} \mathrm{~g} \mathrm{~mol}^{-1}\right)$ & $2.84 \times 10^{2} \pm 3.47 \times 10^{1}$ & 12 \\
\hline$a_{3}\left(\min ^{-1}\right)$ & $2.02 \times 10^{-4} \pm 2.74 \times 10^{-5}$ & 14 \\
\hline$a_{4}\left(\min ^{-1}\right)$ & $5.45 \times 10^{-5} \pm 2.48 \times 10^{-5}$ & 45 \\
\hline$a_{5}\left(\min ^{-1}\right)$ & $3.91 \times 10^{-6} \pm 9.48 \times 10^{-6}$ & 242 \\
\hline$a_{6}\left(\min ^{-1}\right)$ & $1.20 \times 10^{-3} \pm 4.61 \times 10^{-4}$ & 38 \\
\hline$b_{1}\left(\mathrm{~g} \mathrm{~mol}^{-1}\right)$ & $1.59 \times 10^{2} \pm 6.73 \times 10^{0}$ & 4 \\
\hline$b_{3}\left(\mathrm{~g} \mathrm{~mol}^{-1}\right)$ & $8.51 \times 10^{1} \pm 1.19 \times 10^{1}$ & 14 \\
\hline$b_{4}\left(\mathrm{~g} \mathrm{~mol}^{-1}\right)$ & $2.27 \times 10^{2} \pm 6.68 \times 10^{1}$ & 29 \\
\hline$b_{5}\left(\mathrm{~g} \mathrm{~mol}^{-1}\right)$ & $6.48 \times 10^{2} \pm 1.56 \times 10^{2}$ & 24 \\
\hline$b_{6}\left(\mathrm{~g} \mathrm{~mol}^{-1}\right)$ & $4.01 \times 10^{1} \pm 4.24 \times 10^{1}$ & 106 \\
\hline
\end{tabular}



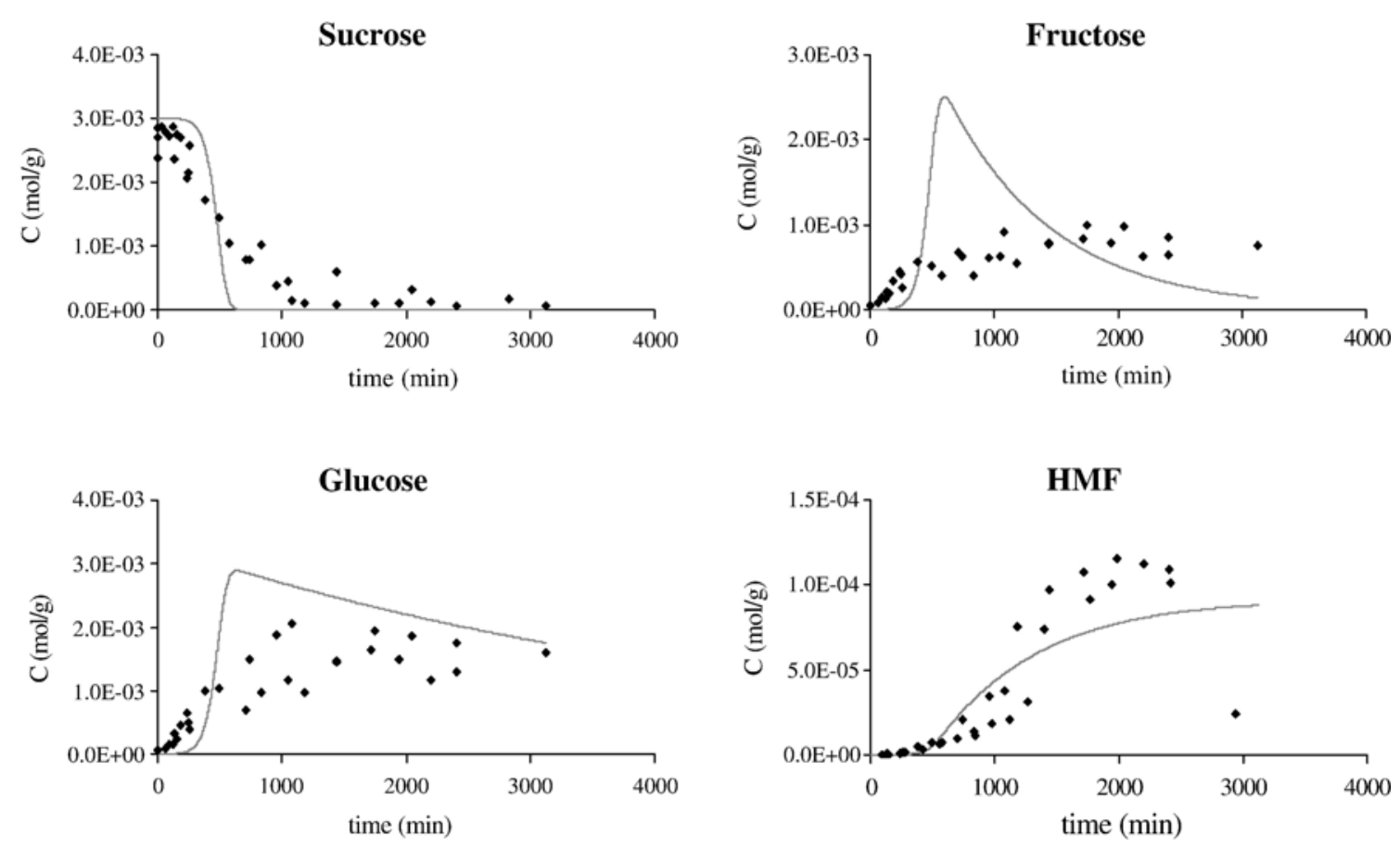

Fig. 5. Typical experimental data and predicted behaviour (using global model - grey lines) of sucrose, fructose, glucose and HMF for a $3.58 \%(w / w)$ water content solution. Example is for a process at $120^{\circ} \mathrm{C}$.

precision, with $\%$ of variation ranging from 2 to $45 \%$. The inferior precision obtained for $\mathrm{a}_{5}$ and $\mathrm{b}_{6}$ may be, once again, justified by the assumption of reaction pathways of components that were not experimentally measured (i.e. other degradation products 1 and 2), hence contributing to mathematical drawbacks in parameter estimation.

Overall, it can be concluded that the proposed model successfully described the experimental data (sucrose solutions from 12.2 to $30.0 \%$ of water content, processed within the temperature range $100-180{ }^{\circ} \mathrm{C}$ ). An example of the global model prediction can be observed in Fig. 2.

\section{Modelin adequacy for reactions occurring a text remely low water} content

As previously justified, experimental data of thermally processed sucrose solutions with $3.58 \%(w / w)$ water content were not included in the development of the proposed models. The ability of the global model to predict sucrose thermal degradation and caramelisation products under such extremely low water content solutions was tested. Experimental results and model predictions can be compared in Fig. 5. As it can be observed, the model does not express the behaviour of caramelisation kinetics. The inadequacy in fructose concentration description may indicate that, at such low water content levels, the reaction step of the fructose carbocation with water to form fructose (described in Fig. 1) is not occurring due to the absence of $\mathrm{H}_{2} \mathrm{O}$ molecules. The fructose carbocation is probably transformed to anhydrofructose under these conditions, as found by other authors (Simkovic, Surina, \& Vrican, 2003). Observed glucose behaviour may indicate that its degradation is favoured under such conditions. Observed HMF behaviour deviation from model prediction can be an indication of the emergence of two possible reaction pathways: i) HMF production from glucose is favoured under such conditions, and/or ii) HMF is a product of non-specific degradation of the fructose carbocation.

\section{Conclusion}

In summary, this work demonstrates the usefulness of multiresponse modelling in understanding reaction mechanisms in food matrices, by elucidating major reaction steps under different conditions and by allowing good prediction of temperature and water content effects. Considering the caramelisation reaction at extremely low water content conditions, further studies should be developed in order to clarify the reaction mechanism.

\section{Acknowledgements}

The authors would like to acknowledge MSc Raquel Mesquita for helping in the total acidity determinations. The present work was supported by the project POCTI/EQU/49194/ 02 "Development of a computational tool to predict the composition of new "sugar free" sweet formulations for traditional Portuguese pastry industry - SWEETCOM" financed by Fundação para a Ciência e a Tecnologia (FCT). Authors M. Quintas and T.R.S. Brandão acknowledge FCT for grants PraxisXXI/BD/20057/99 and SFRH/BDP/11580/2002, respectively. 


\section{References}

Antal Jr., M. J., Mok, W. S. L., \& Richards, G. N. (1990). Mechanism of formation of 5-(hydroxymethyl)-2-furaldehyde from fructose and sucrose. Carbohydrate Research, 199(1), 91-109.

Arena, E., Fallico, B., \& Maccarone, E. (2001). Thermal damage in blood orange juice: Kinetics of 5-hydroxymethyl-2-furancarboxaldehyde formation. International Journal of Food Science and Technology, 36(2), $145-151$.

Barros, R. M., \& Malcata, F. X. (2004). A kinetic model for hydrolysis of whey proteins by cardosin a extracted from cynara cardunculus. Food Chemistry, 88(3), 351-359.

Bates, D., \& Watts, D. (1988). Non-linear Regression Analysis and Its Applications. New York: John Wiley \& Sons.

Bell, L. N., \& Labuza, T. P. (1994). Influence of the low-moisture state on $\mathrm{pH}$ and its implication for reaction kinetics. Journal of Food Engineering, 22(1-4), 291-312.

Box, G. E. P., \& Draper, N. R. (1965). The bayesian estimation of common parameters from several responses. Biometrika, 52(3,4), 355-365.

Box, G. E. P., \& Hunter, W. G. (1965). The experimental study of physical mechanisms. Technometrics, 7(1), 23-42.

Braga da Cruz, I., MacInnes, W. M., Oliveira, J. C., \& Malcata, F. X. (2002). Supplemented state diagram for sucrose from dynamic mechanical thermal analysis. In H. Levine (Ed.), Amorphous food and pharmaceutical systems (pp. 59-70). Cambridge: The Royal Society of Chemistry.

Buera, M. P., Chirifie, J., Resnik, S. L., \& Wetzler, G. (1987). Non-enzymatic browning in liquid model systems of high water activity: Kinetics of color changes due to Maillard's reaction between different single sugars and glycine and comparison with caramelization browning. Journal of Food Science, 52(4), 1063-1066.

Clarke, M. A., Edye, L. A., \& Eggleston, G. (1997). Sucrose decomposition in aqueous solution, and losses in sugar manufacture and refining. Advances in Carbohydrate Chemistry and Biochemistry (pp. 441-470).

Cohen, E., Birk, Y., Mannheim, C. H., \& Saguy, I. S. (1994). Kinetic parameterestimation for quality change during continuous thermal-processing of grapefruit juice. Journal of Food Science, 59(1), 155-158.

Defaye, J., \& García-Fernández, J. M. (1995). The oligosaccharide components of caramel. Zuckerindustrie, 120(8), 700-704.

Eggleston, G., Trask-Morrel, B., \& Vercellotti, J. R. (1996). Use of differential scanning calorimetry and thermogravimetric analysis to characterize the thermal degradation of crystalline sucrose and dried sucrose-salt residues. Journal of Agricultural and Food Chemistry, 44(10), 3319-3325.

Haralampu, S. G., Saguy, I. S., \& Karel, M. (1985). Estimation of Arrhenius model parameters using three least squares methods. Journal of Food Processing and Preservation, 9(3), 129-143.

Karel, M. (1993). Temperature-dependence of food deterioration processes. Journal of Food Science, 58(6), ii.

Knol, J. J., Van Loon, W. A. M., Linssen, J. P. H., Ruck, A. L., Van Boekel, M., \& Voragen, A. G. J. (2005). Toward a kinetic model for acrylamide formation in a glucose-asparagine reaction system. Journal of Agricultural and Food Chemistry, 53(15), 6133-6139.

Kouassi, K., \& Roos, Y. H. (2001). Glass transition and water effects on sucrose inversion in noncrystalline carbohydrate food systems. Food Research International, 34(10), 895-901.

Kroh, L. W. (1994). Caramelisation in food and beverages. Food Chemistry, 51 (4), 373-379.

Labuza, T. P., Tannenbaum, S. R., \& Karel, M. (1970). Water content and stability of low moisture and intermediate-moisture foods. Food Technology, 24(5), 543-548.
Lee, H. S., \& Nagy, S. (1988). Relationship of sugar degradation to detrimental changes in citrus juice quality. Food Technology, 42(10), 91-97.

Lowary, T. L., \& Richards, G. N. (1988). Effects of impurities on hydrolysis of sucrose in concentrated aqueous solutions. International Sugar Journal, 90 (1077), 164-167.

Malcata, F. X. Hill Jr., C. G., \& Amundson, C. H. (1991). Use of a lipase immobilized in a membrane reactor to hydrolyze the glycerides of butteroil. Biotechnology and Bioengineering, 38(8), 853-868.

Manley-Harris, M., \& Richards, G. N. (1997). Dihexulose dianhydrides. Advances in Carbohydrate Chemistry and Biochemistry (pp. 207-266).

Mauch, W. (1971). Chemical properties of sucrose. Sugar Technology Reviews, 1, 239-290.

Nabais, R. M., \& Malcata, F. X. (1997). Modelling of lactic fermentation of carrot slices in salted brines. Food Science and Technology International, 3(4), 263-283.

Peleg, M. (1992). On the use of the WLF model in polymers and foods. Critical Reviews in Food Science and Nutrition, 32(1), 59-66.

Quintas, M., Brandão, T. R. S., \& Silva, C. L. M. (2007). Modelling autocatalytic behaviour of a food model system - sucrose thermal degradation at high concentrations. Journal of Food Engineering, 78(2), 537-545.

Richards, G. N. (1986). Initial steps in thermal degradation of sucrose. International Sugar Journal, 88(1052), 145-148.

Saguy, I., \& Karel, M. (1980). Modelling of quality deterioration during food processing and storage. Food Technology, 34(2), 78-85.

Saraiva, J., Oliveira, J. C., Hendrickx, M., Oliveira, F. A. R., \& Tobback, P. (1996). Analysis of the inactivation kinetics of freeze-dried a-amylase from bacillus amyloliquefaciens at different moisture contents. LebensmittelWissenschaft und-Technologie, 29(3), 260-266.

Schoebel, T., Tannenbaum, S. R., \& Labuza, T. P. (1969). Reaction at limited water concentration - 1. Sucrose hydrolysis. Journal of Food Science, 34(4), 324-329.

Seber, G. A. F., \& Wild, C. J. (1989). Non-linear Regression. New York: John Wiley \& Sons, Inc.

Simkovic, I., Surina, I., \& Vrican, M. (2003). Primary reactions of sucrose thermal degradation. Journal of Analytical and Applied Pyrolysis, 70(2), 493-504.

Slade, L., \& Levine, H. (1991). Beyond water activity: Recent advances based on an alternative approach to the assessment of food quality and safety. Critical Reviews in Food Science and Nutrition, 30(2,3), 115-360.

Stewart, W. E., Caracotsios, M., \& Sorensen, J. P. (1992). Parameter estimation from multiresponse data. AIChE Journal, 38(5), 641-650.

Torres, C. F., Lessard, L. P., \& Hill, C. G. (2003). Lipase-catalyzed esterification of conjugated linoleic acid with sorbitol: A kinetic study. Biotechnology Progress, 19(4), 1255-1260.

van Boekel, M. (1998). Effect of heating on Maillard reactions in milk. Food Chemistry, 62, 403-414.

van Boekel, M. (1999). Testing of kinetic models: Usefulness of the multiresponse approach as applied to chlorophyll degradation in foods. Food Research International, 32(4), 261-269.

van Boekel, M. A. J. S. (1996). Statistical aspects of kinetic modeling for food science problems. Journal of Food Science, 61(3), 477-485.

Vukov, K. (1965). Kinetic aspects of sucrose hydrolysis. International Sugar Journal, 67, 172-175.

www.athenavisual.com 